\section{Patrimonio cultural y memoria. El giro social de la memoria}

Cultural heritage and memory. The social spin of memory

\author{
LUIS Alegría-LiCUIME* \\ Pía Acevedo-Méndez ${ }^{*}$ \\ Carlos Rojas-Sancristoful ${ }^{* \star}$
}

\section{Resumen}

El artículo da cuenta de la vinculación entre el campo del patrimonio cultural y la categoría de la memoria. Se abordan conceptos claves para comprender de manera más compleja el fenómeno del patrimonio cultural y especialmente, como la noción de memoria, ha permitido abrir y tensionar la categoría rígida, monumental y elitista del patrimonio cultural.

En segundo lugar, se abordan dos casos puntuales, la emergencia del campo del patrimonio de la memoria histórica o patrimonio

\footnotetext{
Jefe de Colecciones Museo Histórico Nacional, luis.alegria@mhn.cl

* Doctoranda Programa Arquitectura y Estudios Urbanos, ptacevedo@uc.cl

*** Investigador Instituto de Estudios Patrimoniales, carlos.rojas.san@ gmail.com
}

y derechos humanos, en especial con la emergencia de los sitios de memoria, esto es espacio o lugares caracterizados por la represión política y que hoy han sido declarados monumentos nacionales. En segundo término, el caso del patrimonio industrial y cómo desde esta categoría ha sido posible poner en valor las memorias obreras, como caso específico se trabaja sobre la Empresa Nacional de petróleo (ENAP) en la zona austral de Chile.

Palabras clave: Memoria, Patrimonio Cultural, Patrimonio Industrial

\begin{abstract}
The article gives an account of the link between the field of cultural heritage and the category of memory. It addresses key concepts for a more complex understanding of the phenomenon of cultural heritage, and especially, as the notion of memory, has opened and tightens the rigid, monumental and elitist category of cultural heritage.

Secondly, two specific cases are dealt with: the emergence of the heritage field of historical or historical memory and human rights, especially with the emergence of memory sites, it's space or places characterized by political repression and that today have been declared national monument. Secondly, the case of industrial heritage and how from this category it has been possible to value workers' memories, as a specific case we work on the National Petroleum Company (ENAP) in the southern zone of Chile.
\end{abstract}

Key Words: Memory, Cultural Heritage, Industrial Heritage 


\section{Introducción}

La reflexión en cuanto al pasado durante las últimas dos décadas en América Latina, particularmente tras los procesos post dictatoriales del subcontinente, ha estado marcada por el denominado boom de la memoria y lo que Beatriz Sarlo denomina de manera más precisa como "cultura de la memoria y giro subjetivo" (Sarlo 2007). Desde esta perspectiva cobra especial relevancia para las ciencias sociales la elaboración que realizan los sujetos respecto de su pasado y los marcos de significación que permiten tal ejercicio. Así también, en el marco de una globalización acelerada desde la década de 1990 en adelante (García Canclini 2008), la dimensión identitaria de las comunidades locales, traducida en culturas particulares, han relevado el tema del patrimonio cultural y su configuración a partir de los marcos de significados producidos por la comunidad.

Contodo, en Chile se han constituido dos campos en los que la memoria se ha transformado en un insumo que dota de significados múltiples y en disputa a determinadas materialidades otrora en uso y fundantes de relatos experienciales de un sujeto: el campo correspondiente a los sitios de memoria (ex centros de detención y desaparición de personas) y el de ex espacios industriales (abandonados por las políticas de desindustrialización)

\section{El Patrimonio cultural y el giro de la memoria}

Referirse al proceso de construcción social del patrimonio cultural implica centrarse en la capacidad que poseen los sujetos sociales de otorgar valor a ciertos objetos, desde nuestro enfoque con la finalidad de que el estudio del patrimonio cultural "encuentra sentido en su democratización y no en la exclusión, en el procesamiento del conflicto y no en el ejercicio de la violencia. En otras palabras, que en la preservación de los valores del patrimonio mucho tiene que ver su democratización, su 'deselitización', la apropiación social, la promoción como interés general, la construcción de un proyecto colectivo, el fortalecimiento del sentido de ciudadanía, entre otros" (Carrión 2000: 17).

Esta suerte de estudio y gestión patrimonial debe ser vista como una apuesta de intervención social de lo patrimonial, como un espacio de disputa y no como un proceso unidireccional, ya que compartiendo en algo la crítica del patrimonio que plantea el historiador Aravena:

\footnotetext{
"La denominada 'gestión patrimonial' constituye la última estrategia modernizadora: convierte en mercancía todo aquello que aún se resistía. Pero esta vez, con mayor evidencia que otras, se obliga a la tarea de nivelar el pasado exhibiendo 'documentos de cultura' y censurando 'documentos de barbarie' -o lo que es igual, los trivializa" (Aravena 2009: 75)
}

También nos parece clave considerar que toda intervención debe ser vista como un proceso de intereses en juego. Ni el patrimonio, nilamemoria, pero por mucho tampoco la historiografía, aseguran una lectura crítica y reflexiva de las condiciones y relaciones de desigualdad que caracterizan la realidad. Como una mejor forma de asumir la complejidad del patrimonio cultural proponemos algunos conceptos claves:

\subsection{Campo Patrimonial:}

"Se define, entre otras formas, determinando lo que está en juego y los intereses específicos, que son irreductibles a lo que se encuentra en juego entre otros campos o a sus intereses propios (no será posible atraer a un filósofo 
con lo que es motivo de disputa entre geógrafos) y que no percibirá alguien que no haya sido construido para entrar en ese campo (cada categoría de intereses implica indiferencia hacia otros intereses, otras inversiones, que serán percibidos como absurdos, irracionales, o sublimes y desinteresados). Para que funcione un campo, es necesario que haya algo que implican el conocimiento y reconocimiento de las leyes inmanentes al juego, de lo que está en juego, etcétera" (Bourdieu 1990: 135-136).

En este caso, creemos que lo que se disputa es la capacidad de producción simbólica de otorgar a 'ciertos' bienes culturales una connotación que los re- significa como 'testimonios legítimos' y 'valorados' de la comunidad.

La constitución del fenómeno patrimonial desde un campo patrimonial, nos remite a su especificidad, al problematizarlo como espacio donde confluye la producción, distribución, intercambio y uso de aquellos bienes que 'caracterizamos' o se han caracterizado como patrimoniales, esto porque, "(...) la eficacia simbólica depende de muchos factores, entre los cuales están la contextualización de los símbolos en prácticas y discursos" (Prats 1997: 29), e indiscutiblemente el soporte del poder, reconociendo a este último, como eje fundamental de lo patrimonial.

Este campo opera sobre la base de estructuras -estructurantes que determinan las reglas o condiciones en las cuales opera la patrimonialización, proceso del cual el museo es una institución clave, por tanto, no se le puede estudiar como un espacio independiente y autónomo de los agentes y las relaciones que genera $y / 0$ por las que se encuentra condicionado, tanto en términos de colaboración como de disputa, porque se inserta en la dialéctica de reproducción y producción del campo patrimonial. La centralidad se define en su rol como agente de producción simbólica.

\subsection{Capital simbólico:}

Lo Patrimonial, puede ser entendido como 'conjunto de valores, creencias y bienes' que conformados y resignificados social $e$ históricamente permiten construir una nueva realidad como expresión de las nuevas relaciones sociales que genera. Lo que se explica porque los bienes que consideramos como patrimoniales no fueron necesariamente concebidos como tales, pero, además, porque la constitución del patrimonio permite la conformación de una nueva realidad, que podría ser considerada como una segunda naturaleza. En tanto, son los sujetos y agentes del presente, entendiéndolos como aquellos que cuentan con la capacidad de valoración y apropiación de los bienes del campo patrimonial, quienes poseen la capacidad de darle valor patrimonial o carácter de ser, bienes patrimonializables.

En definitiva, es otorgarles un nuevo significado simbólico, reforzando que quienes pueden ejercer esta capacidad de significación sólo estarán haciendo uso, de una capacidad dada en el campo presente de la producción. Estos sujetos y agentes ejercerán una arbitrariedad cultural, pero que al ser institucionalizada perderá su condición de arbitrariedad cultural. Es decir, podemos hablar de una doble arbitrariedad cultural, en el caso de que muchos 'patrimonios' están conformados por bienes de distinción social, que terminan jerarquizados como bienes de distinción simbólica. Esta serie de interrogantes sobre las dinámicas de funcionamiento de lo patrimonial, nos parecen válidas para aplicarlas a los museos y el patrimonio que custodia.

El capital simbólico se presentará de dos formas nos plantea Bourdieu, como capital 
simbólico objetivado y capital simbólico difuso. La diferenciación entre un capital simbólico difuso basado en el reconocimiento social, y un capital simbólico objetivado, caracterizado por ser codificado, delegado y garantizado por el Estado, es un punto crucial en el entendimiento de la dinámica del campo patrimonial. Será este capital simbólico objetivado, el que encontraremos preferentemente en los museos, como elemento de consagración de una dinámica de arbitrariedad cultural y violencia simbólica transformada en legitimidad cultural.

Ahora bien, entre capital simbólico difuso y objetivado existirá una relación estrecha, ya sea de exclusión o de inclusión, pues dependiendo de las características del proceso de patrimonialización, encontraremos que ciertos bienes pueden transitar de un capital simbólico difuso a uno objetivado, pero no tenemos por qué asumir a priori que ese será una condición única de los bienes que hoy denominamos como patrimoniales, por ello es destacable su diferenciación.

Por arbitrariedad cultural, entendemos toda acción social como resultado de la distinta relación de poder y capacidad jerárquica que selecciona significados culturales de ciertos grupos sociales, por sobre los significados culturales de otros grupos. Mientras que por violencia simbólica, podemos entender toda acción social expresada en las relaciones de fuerza que dentro de una sociedad se expresa en dinámicas de exclusión, invisibilización y discriminación de prácticas y significados culturales de grupos sociales subalternizados en las relaciones sociales de poder estructuradas e institucionalizadas al interior de la misma sociedad.
Los bienes patrimoniales al representar sólo a aquellos que están en condiciones de apropiárselos, estarán representando a sujetos situados desigualmente en la estructura social. Estos grupos conformarán un sistema de significados, sistema que pasa a ser el 'código cultural' de aquella sociedad. Y, por tanto, lo que buscará como sector, o sujeto con capacidad de apropiación de los 'bienes patrimoniales' será otorgarles la característica de universalidad, la cultura legítima, o sea, la cultura dotada de legitimidad dominante, no es más que la arbitrariedad cultural dominante, en la medida en que se desconoce su verdad objetiva de arbitrariedad cultural y de arbitrariedad cultural dominante (Bourdieu y Passeron 1979).

\subsection{Patrimonialización:}

Proceso mediante el cual un objeto o práctica cultural adquiere la significación de patrimonio. En este proceso, varios serán los mecanismos que permitirán la configuración de lo patrimonial. Sin duda, muchos de los momentos cruciales de la construcción de patrimonio se dan en el interior del museo, configurando latrascendencia dicha institución en la transmisión y legitimidad cultural de la sociedad.

La conservación, preservación y difusión serán durante mucho tiempo las funciones y mecanismos exclusivos desarrollados en el museo para la puesta en valor del patrimonio, en este caso de objetos, como únicos bienes posibles de musealizar. Situación que ha variado de manera significativa en el último tiempo, dándose un giro que cuestiona el rol casi exclusivista del museo en los procesos de patrimonialización, por eso hoy es posible encontrar procesos donde las propias comunidades asumen la tarea de construir 
patrimonio, sin necesariamente tener como referente al museo.

\subsection{Construcción/Invención:}

Asumir la idea antropológica de patrimonio nos habla de este como una construcción social. El proceso de construcción lo entendemos, como un proceso con cierto grado de legitimidad social, a diferencia del proceso de invención que significaría aquel mediante el cual la arbitrariedad y manipulación corresponderían a sus elementos principales, asumiendo que en la realidad ambas características se superponen en muchos casos, nos parece fundamental identificar y diferenciar dichos procesos en la conformación del patrimonio.

Para el caso de la noción de invención nos parece clave la distinción realizada por Hobsbawm y Ranger;

\footnotetext{
"La 'tradición inventada' implica un grupo de prácticas, normalmente gobernadas por reglas aceptadas abierta o tácitamente y de naturaleza simbólica o ritual, que buscan inculcar determinados valores o normas de comportamiento por medio de la repetición, lo cual implica automáticamente continuidad con el pasado. De hecho, cuando es posible, normalmente intentan conectarse con un pasado histórico que les sea adecuado" (Hobsbawm y Ranger 2002).
}

A continuación, proponemos dos casos donde es posible dar cuenta de una vinculación específica entre patrimonio cultural y memoria, la relevancia de los casos se basa en dar cuenta como el patrimonio cultural se transforma en un recurso para generar nuevas e innovadoras miradas sobre la realidad social. Por un lado, todo el campo nuevo que se ha abierto en el cruce entre derechos humanos, memoria y patrimonio cultural, y por otro, como a través de la noción de patrimonio industrial es posible abordar, investigar y en definitiva poner en valor las memorias obreras, en este ejemplo puntual la experiencia de las memorias obreras de la Empresa ENAP en la zona austral de Chile.

\section{Memoria, Derechos Humanos y Patrimonio.}

Como señala Elizabeth Jelin (2003) las preocupaciones políticas por la democracia de los nuevos movimientos sociales, las reflexiones sobre la ciudadanía y la constitución de la subjetividad ciudadana son un producto y aporte fundamental de la lucha del movimiento de derechos humanos que logran situarlos como parte de una ética y punto de partida de un nuevo marco interpretativo en la esfera pública a la hora de pensar la relación entre Estado y sociedad, además de los mecanismos y articulaciones entre el plano de las condiciones materiales, las instituciones, la subjetividad y el nivel simbólico-cultural:

\begin{abstract}
"La memoria y el olvido, la conmemoración y el recuerdo, se tornan cruciales cuando se vinculan a acontecimientos traumáticos de carácter político y a situaciones de represión y aniquilación, cuando se trata de profundas catástrofes sociales y situaciones de sufrimiento colectivo. En lo individual, la marca de lo traumático interviene de manera central en lo que el sujeto puede y no puede recordar, silenciar, olvidar o elaborar. En un sentido político, las cuentas con el pasado" (Jelin 2003: 23).
\end{abstract}

De esta manera, entendemos el patrimonio cultural como un conjunto de valores, creencias y bienes materiales e inmateriales que conformados y resignificados social e históricamente permiten construir una nueva realidad como expresión de las nuevas relaciones sociales que genera. Esto se explica porque los bienes que consideramos como patrimoniales no fueron necesariamente concebidos como tales, siendo los sujetos y 
agentes del presente, entendiéndolos como aquellos que cuentan con la capacidad de valoración y apropiación de los bienes del campo patrimonial, quienes poseen la capacidad de darle valor patrimonial o carácter de ser bienes patrimonializables.

Aquel proceso se conceptualiza como patrimonialización, entendido como el conjunto de iniciativas y prácticas de producción de patrimonio cultural, cuyo inicio se expresa cuando individuos, instituciones o comunidades deciden, mediante un proceso de selección o valoración, que ciertos objetos o lugares merecen ser preservados, que representan algo sobre sí mismos y su pasado que debería ser transmitido a las generaciones futuras (Hernández 2008).

La interacción entre territorio y memoria, entendida como la constante resignificación del pasado, transforma un lugar sin significación aparente en un lugar de memoria, que puede ser potencialmente patrimonializables por una comunidad. En particular el Instituto de Políticas Públicas de Derechos Humanos del Mercosur (IPPDH) como estos lugares como:

"Sitios donde sucedieron los acontecimientos o que, por algún motivo, están vinculados con dichos acontecimientos- son espacios para recuperar, repensar y transmitir ciertos hechos traumáticos del pasado, y pueden funcionar como soportes o propagadores de memoria colectiva. Son sitios que buscan transformar ciertas huellas de manera de un relato más amplio" (IPPDH 2012: 6).

En esa misma línea se destaca el potencial pedagógico de estos lugares, en tanto:

"Las memorias que una sociedad tiene respecto de los sucesos ocurridos en el pasado son producto de una tarea colectiva de elaboración y construcción permanente, de intentos de imposición de significados, cuyo resultado siempre se presenta como precario, susceptible de ser redefinido. Aquí reside el carácter conflictivo inherente a la concepción misma de memoria colectiva. $Y$ allí radica también la importancia (pedagógica y política) de los trabajos de memoria relativos a un pasado signado por la violencia estatal que intentan procesar y evitar su reemergencia a la vez que a construir y reforzar identidades comunes" (IPPDH 2012: 6).

A su vez, Nora entiende los lugares de memoria, como pertenecientes a una dimensión polifónica, que es lo que es confiere interés, pero también complejidad:

“(...) simples y ambiguos, naturales y artificiales, abiertos inmediatamente a la experiencia más sensible, y al mismo tiempo, fruto de la elaboración más abstracta. Son lugares en tres sentidos, materiales, simbólicos y funcionales. Una unidad significativa de orden material o ideal en la cual la voluntad del hombre o el trabajo del tiempo hace un elemento simbólico de un grupo determinado" (Nora 2009: 32)

En este sentido las acciones sociales implementadas en el campo de la memoria se caracterizan por ser,

“(...) procesos sociales que consisten en identificar el gesto fundador -y su sentido- mediante el cual actores de memoria -ya sea que representen poderes públicos, ciudadanos (agrupados o no en colectivos) o víctimas -hacen de un lugar el sitio emblemático de una historia de la que deciden conmemorar un aspecto. Así como en un marco judicial, la calificación de un hecho permite aplicar al autor una sanción correspondiente, el hecho de nombrar un lugar los inscribe de manera particular en una historia y permite a quienes (antiguas víctimas o sus representantes, políticos, miembros de asociaciones...) se encargan de su dimensión conmemorativa atribuirle un régimen de valores y una semántica" (Feury y Walter 2011: 23)

Un ejercicio clave es el reconocimiento de las distintas formas que adquieren los procesos de memorialización en el territorio a la hora de vincular educación y memoria. Para efectos del programa TU MEMORIAL hemos identificado cuatro niveles de un mismo proceso: 
Nivel 1. Marcas represivas (Silva y Rojas 2005):

-Lugares secretos de detención y tortura, la mayor parte insertos en el funcionamiento normal de la ciudad. Los prisioneros permanecían completamente incomunicados y sometidos a interrogatorios bajo tortura, además de deplorables condiciones de subsistencia.

-Lugares de detención donde no se aplicaba tortura: lugares de espera o de tránsito hacia otros recintos donde se realizaban interrogatorios y se aplicaba tortura.

-Campamentos de detenidos, también llamados "campos de concentración", creados a partir de 1973. Eran de conocimiento público y se permitía el contacto entre los prisioneros e incluso con sus visitas.

-Recintos de detención pertenecientes a instituciones: recintos de dependencia institucional de carácter público.

-Cárceles y penitenciarías: lugares de reclusión para prisioneros comunes, utilizados para encarcelar a presos políticos sometidos a procesos y condenados. En algunos casos, se practicó la tortura o la desaparición de algunos detenidos.

-Recintos para el funcionamiento interno de los servicios de seguridad, destinados a actividades administrativas, habitacionales y de entrenamiento de los agentes perpetradores.

\section{Nivel 2. Acciones de ocultamiento (Silva y Rojas 2005):}

-Demolición: se trata de una acción de destrucción del lugar. Caso de la casa José
Domingo Cañas (centro secreto de detención y tortura).

-Ocultamiento: cuando las actividades rutinarias u otras ocultan las acciones de represión, por ejemplo: el Estadio Nacional (centro secreto de detención y tortura).

-Apropiación y simulación: se trata de una acción de disfrazar la identidad del sitio, por ejemplo, con el cambio de numeración; caso de Londres 38 o Londres 40 (centro secreto de detención y tortura).

-Aislamiento: se refiere a barreras geográficas o de accesibilidad, que impiden el acceso al lugar físico. Caso Isla Dawson (Campo de concentración).

-Desconocimiento: hablamos de lugares donde no se ha producido ningún registro de su uso como centro de detención y tortura. Caso Simón Bolívar (centro de exterminio que no dejó sobrevivientes).

\section{Nivel 3. Acciones de memoria (Feury y Walter 2011):}

-Recuperar: esta acción implica que un espacio que fue enajenado de sus funciones iníciales por la dictadura al instalar allí centros públicos o clandestinos, de detención, tortura y exterminio; es vuelto a enajenar, pero esta vez por las víctimas, sus familiares o activistas. Consiste en expropiar, esto es enajenar de las manos de los perpetradores (o de las instituciones que siguieron funcionando allí, muchas veces vinculadas con las fuerzas represivas) para convertirlo en un lugar que debería dedicarse a homenajear a las víctimas y servir para rememorar lo acontecido. 
-Rescatar: recuperar de la destrucción, ya sea la que voluntariamente fue afectada por los responsables de los crímenes, como aquella debida al desgaste del tiempo los restos materiales de aquellas edificaciones.

-Salvaguardar: recuperar las huellas que aún pueden observarse para que sirvan como pruebas en los juicios por crímenes de lesa humanidad.

-Señalar: mostrar el sitio a los vecinos y la comunidad, la historia teñida de sangre de esos lugares incluidos en la aparente "normalidad" de la trama urbana.

-Abrir: el espacio es abierto para un uso público y comunitario; operar como vehículos en la tarea de transmisión de la memoria hacía las próximas generaciones.

-Resignificar: transformar ese lugar de muerte en un espacio que alberga nuevos proyectos vitales, creativos, artísticos y culturales.

\section{Nivel 4. Memorialización y puesta en valor (Adaptado de Silva y Rojas 2005):}

-Reproducción: Posee como finalidad la exhibición del horror. Son acciones enmarcadas en un registro objetivista del pasado. Por lo general, los efectos de estas acciones en la comunidad son el bloqueo y distanciamiento.

-Símbolo: Su objetivo es metaforizar el hecho, de esta forma se evita hablar directamente del horror, en algunos casos como una forma de proteger a las víctimas de un nuevo proceso de revictimización, en otros, como una opción para posibilitar la discusión reflexiva y crítica de sucesos traumáticos de gran impacto.
Uno de sus efectos no buscados, es que el traspaso de la vivencia a una representación conceptual pierde el significado vital de la propia experiencia.

-Placa recordatoria: En estas iniciativas la memoria se transforma en una marca en el territorio. Situadas en el espacio público se constituyen en dispositivos mnemotécnicos de gran eficiencia, en especial en comunidades sensibilizadas con el contexto y ciertos hechos, así como convocan a la curiosidad de aquellos no informados. Una de sus críticas podría ser el peligro de transformar la memoria del hecho en un dato, que podría archivarse como tal.

-Memorial: Hite, nos plantea que:

\footnotetext{
"Las políticas de la conmemoración admiten que los procesos conmemorativos son algo más que ejercicios simbólicos de reconocimiento del pasado. La memorialización puede transformar los significados del pasado y movilizar el presente" (2013: 20).
}

En ese sentido, el memorial podría devenir en sitio de memoria, esto superar la mera acción conmemorativa a través de un conjunto de acciones que fomenten reflexiones y reelaboraciones sobre el pasado. En muchos casos el memorial tiene como única intención la conmemoración, donde se recuerda el dato y se deja fuera la vivencia.

-Musealización/museificación: En el primer caso:

"Siguiendo a Stránský, es el proceso por el cual un objeto, en su sentido más diverso, se transforma en testimonio material o inmaterial del ser humano y de su medio ambiente, fuente de estudio y de exposición, adquiriendo así una realidad cultural específica. La musealización, como proceso científico, abarca el conjunto de actividades del museo: el trabajo de preservación (selección, adquisición, gestión, conservación), de investigación 
(del que surge la catalogación) y de comunicación (por medio de la exposición, las publicaciones, etc.) o bien, desde otro punto de vista, las actividades vinculadas a la selección, la tesaurización y la presentación de aquello que se ha transformado en musealia" (Desvallées y Mairesse 2009: 50).

A su vez la museificación, es un neologismo que traduce la idea peyorativa de 'petrificación' o 'momificación' de un lugar viviente y se encuentra reflejado en numerosas críticas vinculadas a la 'musealización del mundo'. Es la objetualización del suceso o acontecimiento, escondiendo su carácter de descontextualización, lo que lo distancia y congela.

\section{Memoria Obrera y Patrimonio Industrial: el caso de la Empresa Nacional del Petróleo (ENAP) en Tierra del Fuego}

\subsection{Descubrimiento del petróleo y la articulación urbana de la isla de Tierra del Fuego}

El 29 de diciembre de 1945 se descubrió petróleo en Chile, particularmente en la isla de Tierra del Fuego. Este hallazgo transformó la situación del extremo sur chileno, ya que no sólo significó un avance en materia productiva, sino que también promovió el cambio urbanístico y demográfico más importante que experimentó la isla desde la instalación de las primeras estancias ganaderas desde fines del siglo XIX. Pasado cinco años desde este hallazgo el Estado de Chile creó, bajo la Ley N9.168, la Empresa Nacional del Petróleo (ENAP), entidad que estuvo a cargo de proveer de maquinara, infraestructura, asentamientos y trabajadores a esta zona logrando, a través de estas obras, densificar y dotar de población humana permanente uno de los territorios más inhóspitos del país (Martinic 2013).
Durante los primeros años de la ENAP se acondicionaron y construyeron los cinco campamentos que posibilitaron la explotación de hidrocarburos en Tierra del Fuego. Así, se levantaron dos terminales marítimos Puerto Percy y Clarencia (1950); además de los campamentos Manantiales (1950), Cerro Sombrero (1958) y Cullén (1962). (fig. 1)

Figura 1. Campamentos petroleros enapinos en Tierra del Fuego.

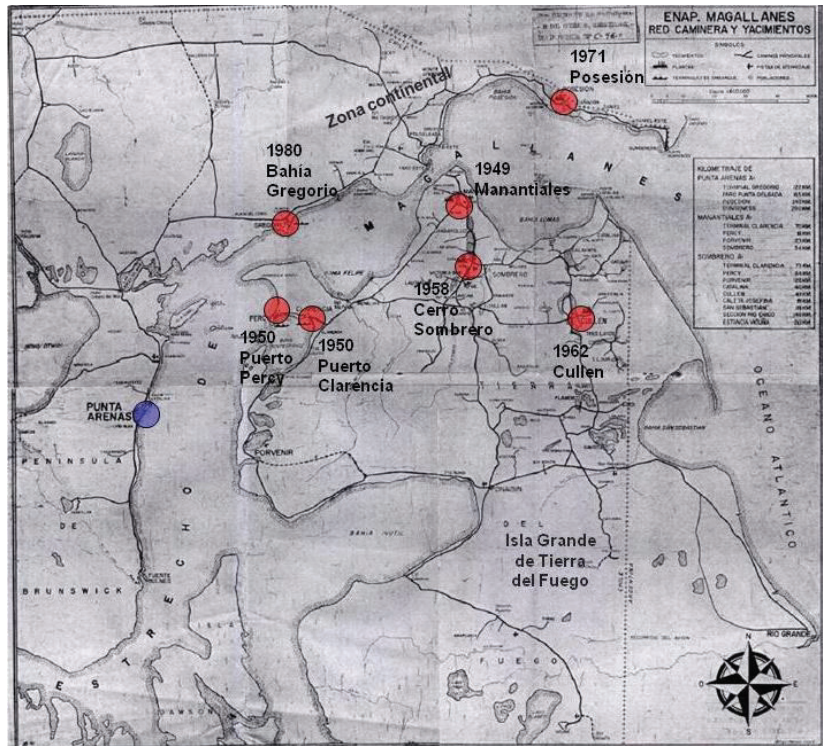

Fuente: Daniel Matus y Boris Cvitanic, 2015.

Estos cinco campamentos se articularon como una gran red de espacios productivos que dieron vida a un "conjunto industrial" (Pardo 2008) interdependiente entre sí y comunicado a través de rutas viales construidas por la misma empresa. Sumado a lo anterior, estos asentamientos se levantaron para surtir de instalaciones a los trabajadores y sus familias 
con las comodidades que cada uno de los integrantes del grupo necesitara para su óptimo desarrollo (Martinic 2013).

De acuerdo a esto, todos los campamentos contaron con casas (fig.2), escuelas (fig.3), policlínicos, cines (fig.4), gimnasios (fig.5), iglesias (fig.6) y cooperativas o pulperías de abastecimiento, entre otros. La construcción de estos espacios estuvo destinada a facilitar la vida en familia, disminuir la sensación de aislamiento y mitigar las carencias que este podía significar, además de potenciar la interacción entre los pobladores y fomentar los vínculos comunitarios (Acevedo y Rojas 2015).

Figura 2. Casas ex campamento Puerto Percy, Tierra del Fuego.

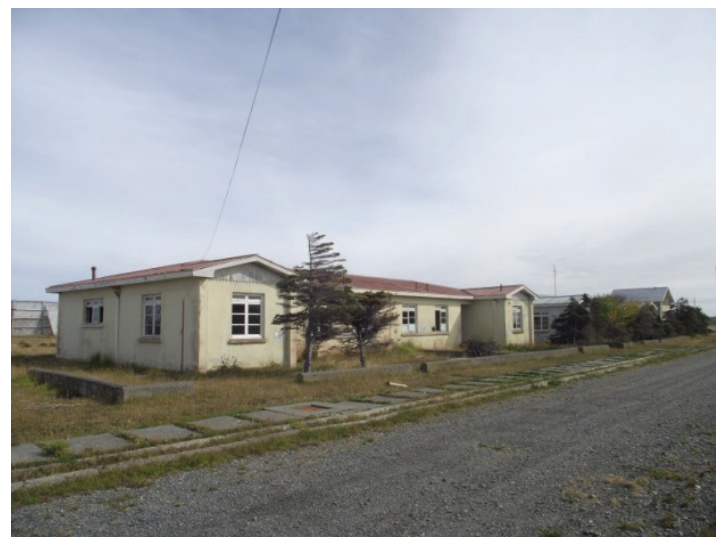

Fuente: Pía Acevedo, 2014.
Figura 3. Escuela ex campamento Puerto Percy, Tierra del Fuego.

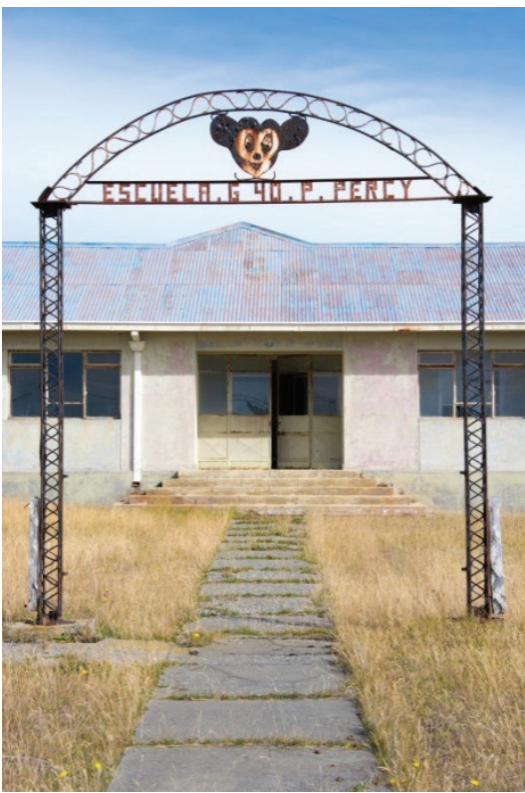

Fuente: Pía Acevedo, 2014.

Figura 4. Cine ex campamento Cerro Sombrero, Tierra del Fuego.

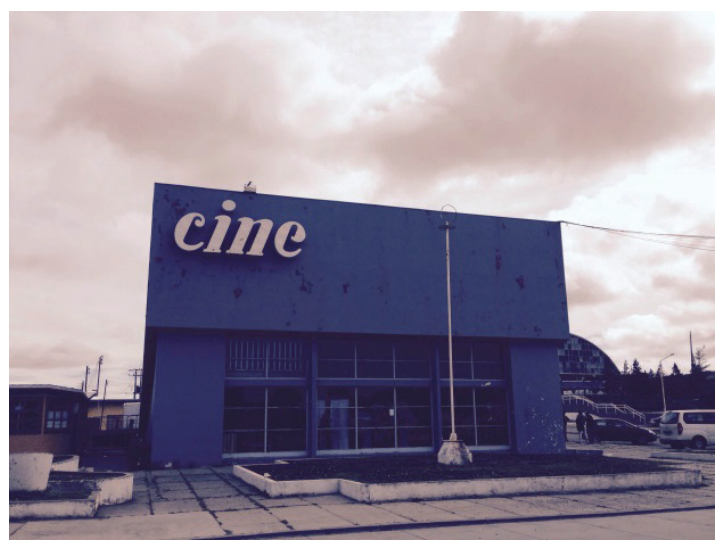

Fuente: Pía Acevedo, 2014. 
Figura 5. Gimnasio ex campamento Manantiales, Tierra del Fuego.

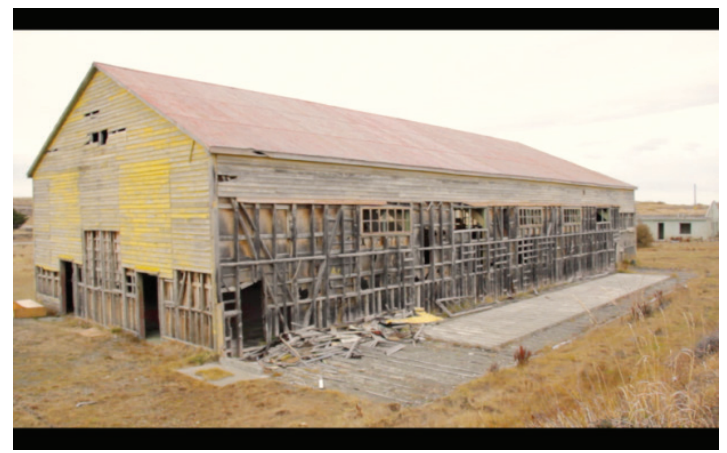

Fuente: Pía Acevedo, 2014.

Figura 6. Iglesia ex campamento Cerro Sombrero, Tierra del Fuego.

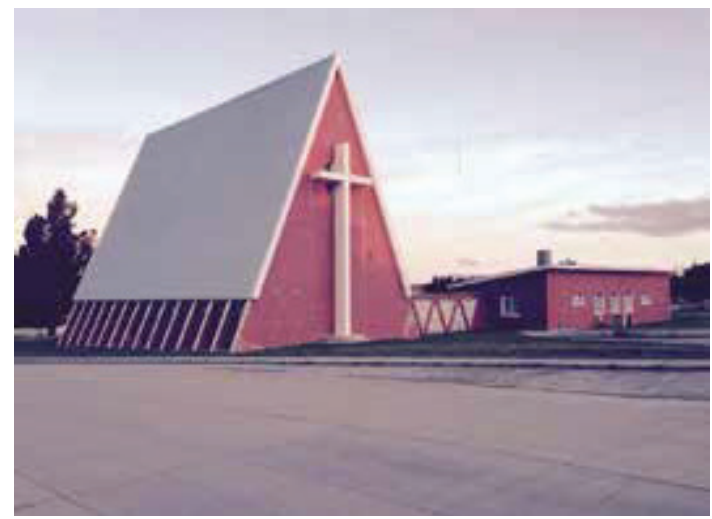

Fuente: Pía Acevedo, 2014.

Si bien el despliegue social y espacial de la ENAP en Tierra del Fuego fue trascendental para su urbanización y densificación demográfica, en la actualidad, la situación es diferente y de los 5 campamentos construidos entre 1950 y 1962 sólo queda habitado Cerro Sombrero, aunque desvinculado administrativamente de la Empresa Nacional del Petróleo. Este ex campamento enapino cumple, ahora, el rol de capital de la comuna de Primavera, creada al igual que su vecina Timaukel, en 1980, para apoyar la presencia del Estado en la zona, ya que hasta antes la creación de estas comunas sólo se había fundado la ciudad de Porvenir (1894) en toda la isla de Tierra del Fuego.

\subsection{La comunidad enapina en los campa- mentos petroleros más australes del mundo}

Previamente a la desocupación de los campamentos petroleros, la ENAP incurría en importantes esfuerzos para que sus trabajadores pudieran sortear el aislamiento y las condiciones climáticas propias de esa zona del país, ofreciendo una serie de dispositivos y actividades de esparcimiento y capacitación en las cuales podían participar los funcionarios de la empresa y todos los integrantes de su familia. Estas actividades estaban orientadas, además, a generar comunidad y fortalecer los lazos entre los diferentes trabajadores y su grupo familiar asentados en cada campamento, gatillando una imbricada relación social entre todos los sujetos enapinos. La difusión de estas instancias también era un tema del que la ENAP se hacía cargo a través de su boletín, denominado "Infórmese", que circuló entre los trabajadores y los campamentos entre 1961 hasta 1990, con algunos intervalos durante la década de 1970. Dentro de este documento, además de lo descrito anteriormente, se podía hallar información concerniente a la producción de petróleo, cambios de autoridades de la petrolera nacional, beneficios habitacionales y educacionales destinados a los trabajadores, entre otras.

En relación a las instancias sociales y comunitarias generadas por la ENAP se 
encontraban el deporte, la cultura y las artes como lo más ofrecido por la empresa y lo más concurrido por parte de los ex habitantes de los campamentos. Así, contaban con una alta adhesión deportes como fútbol, voleibol, basquetbol, palitroque, truco, piscina y caza deportiva, entre otros. En relación a la cultura, a nivel campamento, se organizaron grupos folclóricos, talleres de teatro, fotografía, pintura y diversas manualidades en los que participaban hombres, mujeres y niños enapinos, ya que existía especial atención a que los familiares de los trabajadores ocuparan sus jornadas en actividades sanas y colectivas.

Para darle un sentimiento comunitario más profundo, la ENAP organizaba algunos encuentros deportivos y culturales de mayor envergadura en los que participaban equipos deportivos y representantes de cada campamento los que tenían la responsabilidad de ganar en nombre de su respectivo asentamiento petrolero y brindarles la alegría del triunfo a los habitantes de ese espacio. En este sentido algunas de las actividades más recordadas fueron las Olimpiadas Enapinas, para el caso deportivo, y el Festival de la Canción Enapina, para el ámbito cultural, que, a través del departamento de bienestar, eran organizadas, logrando reunir a todos los habitantes de los distintos campamentos en pos de estos eventos.

Cada tanto, a través de su boletín, la ENAP mantenía informados a los enapinos sobre su visión en relación a estas actividades, dejando entrever lo relevante que le significaban:

"El experimentado y competente personal de bienestar prepara minuciosamente los programas para las próximas contiendas en las diferentes ramas deportivas, sin descuidar los actos sociales y culturales. Mantienen activa la mente y conciencia enapina combatiendo la inactividad que a veces produce el frío y la distancia: atraen a los pobladores a los gimnasios, exigen a los directivos de los diferentes clubes deportivos a preparar sus equipos para las competencias de la nueva temporada de 1967" (Boletín Infórmese 1967: 4).

La vida comunitaria enapina se nutría de deporte y cultura, pero también de una serie de acontecimientos que eran celebrados de manera importante por la ENAP. Entre los acontecimientos propiamente petroleros, se destaca el descubrimiento del petróleo, celebrado cada 29 de diciembre hace 71 años y la creación de la ENAP, que es conmemorada cada 19 de junio desde 1950. Otros hitos que no se relacionan directamente con el pasado del petróleo, pero que si poseen un rol trascendente a nivel social también eran celebrados por la empresa tales como la navidad, las fiestas patrias y el año nuevo. Estos tres eventos eran esperados por la comunidad enapina y ampliamente aplaudidos por ella, ya que que veían en estos el compromiso y la cercanía que tenía la empresa para con ellos y, en el caso de la navidad, para con sus hijos.

En general, la empresa estaba presente en cada uno de los momentos de la vida de sus trabajadores, generando una especie de "omnipresencia" que fue crucial en la configuración de la comunidad enapina, que remite su denominación, precisamente a su relación estrecha con la ENAP. Aparte de las diversas celebraciones y actividades y de proveer de lo necesario - vivienda, educación, salud y esparcimiento- para que los trabajadores se desempeñaran junto a sus familias en lugares apartados como lo es Tierra del Fuego, la empresa consideraba, de vez en cuando, enviar mensajes orientado a fortalecer el sentimiento de orgullo que significaba vivir en 
Magallanes, trabajar en la industria del petróleo y por sobre todo trabajar en una empresa del Estado única en su tipo, ocupando para esto el boletín "Infórmese":

\begin{abstract}
"Para el enapino magallánico es común escuchar comentarios de sus relaciones o compañeros que laboran en otras zonas del país como estos que insertamos: - ¿pero cómo pueden vivir en campamentos?. ¡Nosotros no podríamos vivir de esa forma!. ¡Preferimos ganar menos, pero vivir en la ciudad-. Y así como estas frases un tanto derrotistas, muchos otros comentarios que no calzan con la realidad. Tal vez esto sea consecuencia de una falsa estimación o de falta de conocimiento relacionado con la organización de la empresa y del funcionamiento que labora en Magallanes. (...) (La empresa) se preocupa de mantener en los centros más apartados de trabajo una secuencia variada de espectáculos que en nada desmerecen a los que se presentan en otras ciudades del país. Muchas veces en sus cines se exhiben películas que son estrenos en Chile. Lo relacionado con artes, folclore, enseñanzas técnicas o especiales son objetivos ya incorporados que capacitan y destacan a sus trabajadores" (Boletín Infórmese 1971: 2).
\end{abstract}

Gran parte de los descrito anteriormente fue la tónica de la ENAP durante la segunda mitad del siglo XX, sin embargo, en la actualidad, aquella modalidad omnipresente que tuvo la empresa, ya no se perfila de esa manera y parte de lo que acostumbró el trabajador enapino por más de cuatro décadas ya no es tal. En este sentido, los campamentos se deshabitaron y una cantidad importante de los trabajadores que, actualmente, continúa en las faenas petroleras se desempeña bajo sistema de turnos y vive en Punta Arenas o Porvenir, situación que facilitó la desarticulación de la política de bienestar de la empresa que estuvo orientada a la satisfacción de las necesidades básicas de los trabajadores y sus familias. Asimismo, la mejora en la conectividad entre el continente y la isla también facilitó que las faenas petroleras se desarrollaran en menor tiempo, posibilitando que los trabajadores ya no tuvieran que vivir en los campamentos, justificando así sus cierres y desmantelamientos.
Lo anterior significa que, a pesar de haberse desarrollado una imbricada vida social, asentada en espacios y asentamientos de características y atributos únicos en su tipo, los cambios de rumbo que tomó la empresa y el actual sistema económico que propende a reducir el gasto empresarial en materia social, llevó a que aquella comunidad enapina se haya visto desarticulada y desarraigada de los espacios que le dieron sentido a su devenir. Actualmente, una cantidad importante de ex trabajadores y ex habitantes de los campamentos enapinos que experimentaron los tiempos de mayor auge de la ENAP se han organizado en pequeños núcleos que les permiten revivir aquél pasado petrolero promisorio y volver a sentir esa sensación de pertenencia de la cual se les despojó producto de las vicisitudes económicas de las que fue objeto la Empresa Nacional del Petróleo.

A raíz de este escenario que enfrenta el devenir petrolero nacional, sumado al bajo interés manifestado por la empresa en resguardar los vestigios de ese pasado industrial es que existe la posibilidad de que en un futuro no lejano el país, prácticamente, desconozca lo que significó el descubrimiento del petróleo para Chile, no sólo en términos productivos y económicos, sino también en aspectos sociales y culturales, que hoy por hoy, poseen una relevancia a la hora de entender la identidad magallánica contemporánea.

En virtud de esto, las memorias enapinas de los ex trabajadores y ex habitantes de los campamentos juegan un rol fundamental en la posibilidad de conocer, comprender y adentrase en lo que significó haber sido parte de la hazaña petrolera en el fin del mundo. 


\subsection{Memorias enapinas: Una oportunidad para generar conocimiento en relación a la industria del petróleo en Tierra del Fuego}

La memoria, configurada como un proceso de representación simbólica sobre acontecimientos del pasado responde, en términos amplios, a un tiempo, un espacio y un grupo determinado que comparte ciertos procesos y que le dan cierto sentido a su presente. En ese sentido, el pasado petrolero logra aglutinar a una cantidad importante de sujetos que compartieron un espacio determinado - campamentos en Tierra del Fuego-, un tiempo en particular- segunda mitad del siglo XX - y que fueron parte de una comunidad que trabajó y vivió en pos del petróleo nacional y que desarrolló códigos que les permitieron legitimarse como tal. De acuerdo a esto, parte de aquellos códigos continúan estando presentes, a pesar de existir un distanciamiento importante de los lugares y del tiempo en los fueron desarrollados.

En estas memorias petroleras se alojan las experiencias enapinas pasadas, basadas en los acontecimientos colectivos que se vivían día a día en los ex campamentos y que, en algunos casos, continúan viviéndose hasta la actualidad, sobre todo lo que se relaciona con eventos conmemorativos como la celebración del 29 de diciembre o la del 19 de junio. Por otra parte, existe una agrupación de ex enapinos, denominada APENAP (asociación de pensionados de ENAP) que cada cierto tiempo se reúnen en cenas y celebraciones, en calidad de ex habitantes de los diferentes campamentos y ex trabajados de la empresa, a rememorar sus experiencias y su pasado petrolero, apelando a que lo que ellos vivieron estando en el Fin del Mundo fue único e irrepetible y que como tal les permite legitimarse en el presente.
A pesar de la organización que han generado algunos ex enapinos para reunirse y recordar su paso por la ENAP y por los campamentos ha existido un bajo interés por parte de investigadores en adentrarse en aquellas memorias y realizar un trabajo riguroso, con metodologías que surjan desde la historia y los estudios de la memoria, para sistematizarlas y generar conocimiento acerca de la industria petrolera nacional, sobre todo considerando que este recurso minero industrial y sus ribetes territoriales, sociales e identitarios gozan de escasa presencia en la historiografía magallánica y nacional. A le fecha el trabajo más reconocido sobre esto es del historiador local Mateo Martinic, quien publicó, gracias a los aportes de la ENAP, "Historia del petróleo magallánico" en 1983 y que estuvo orientado a revisar el impacto productivo de este recurso en la zona. Desde entonces no han existido otros trabajos abocados a reconstruir la historia del petróleo y, menos aún, a revisar la historia social y la memoria de esta industria nacional.

Otro de los desafíos que enfrentan estas memorias es lo que guarda relación con los espacios de memoria del petróleo, materializados en los campamentos y en la infraestructura productiva. Tal como se planteó anteriormente, los campamentos fueron desmantelados y deshabitados y en la actualidad se encuentran en una situación de abandono e importante deterioro que amenaza diariamente su perduración en el tiempo. Esto significa que un plazo no muy lejano las memorias enapinas podrían carecer de los espacios y las estructuras arquitectónicas sobre que les permitieron surgir, situación que sería perjudicial para el conocimiento sobre la situación petrolera magallánica, ya que la memoria obrera $y$, para este caso, petrolera no debe disociarse de los espacios en los que emergieron y en los que, en la actualidad, se cimentan. 
A modo de conclusión, independiente de que la memoria posea una serie de cuestionamientos como su nivel de objetividad o exactitud respecto del pasado y del recuerdo que de este configura, es innegable plantear que ofrece una serie de posibilidades para comprender un pasado que determinó el presente de un grupo en particular. Si se considera la aplicación de metodologías apropiadas, las memorias enapinas -para el caso petrolero- podrían perfilarse como una de las fuentes más importantes para conocer el pasado petrolero de la región de Magallanes, sobre todo sabiendo que existe una baja cantidad de trabajos asociados a esta temática.
Además de esto, es necesario considerar también que para que la memoria siga articulándose necesita de espacios, o al decir de De Certeau (2000) de 'lugares practicados' que le permitan legitimarse y, en ese sentido, la ENAP y los ex enapinos, así como también los magallánicos y la ciudadanía en general tiene una deuda con los espacios petroleros, sobre todo con los levantados en Tierra del Fuego que gozan de ser únicos en su tipo y los más australes del mundo, ya que están a la orden del abandono, del deterioro y de la falta de gestión y acciones que permitan su restauración, pero por sobre todo su conservación.

\section{Bibliografía}

Acevedo, Pía y Rojas, Carlos (Editores), 2015. Enapinos. Los campamentos petroleros del Fin del Mundo. Un patrimonial Industrial por armar. Etapa fundacional (1945-1962).SantiagoChile: Consejo Nacional de la Cultura y las Artes.

Aravena, Pablo, 2009. "Memorialismo, historiografía y política. El consumo del pasado en una época sin historia", Concepción: Editorial Escaparate.

Bourdieu, Pierre, 1990. Sociología y Cultura. México D.F.:Grijalbo. Primera Edición.

Bourdieu, P., y Passeron, J., 1979. "La Reproducción. Elementos para una teoría del sistema de enseñanza". México D.F.: Fontamara.

Carrión, Fernando, 2000. "El Gobierno de los Centros Históricos". Desarrollo Cultural y gestión de centros históricos. Torres, A. (Ed.), Quito-Ecuador: FLACSO.

De Certeau, Michel. 2000. La invención de lo cotidiano I. Artes de hacer. México: Universidad Iberoamericana, Instituto Tecnológico y de Estudios Superiores de Occidente.

Desvallées A., y Mairesse, F., 2010."Conceptos claves de museología" Francia: Editorial Armand Colin.

Domínguez, P., 2011. Cerro Sombrero, Arquitectura Moderna en Tierra del Fuego. Santiago: Consejo Nacional de la Cultura y las Artes.

Fleury, B. y Walter, J. 2011. "De los lugares de sufrimiento a su memoria". Memorias de la piedra. Ensayos en torno a lugares de detención y masacre. Fleury y Walter (Comp.) Argentina: Ejercitar las memorias Ediciones.

García Canclini, N., 2008. Culturas Híbridas. Estrategias para entrar y salir de la Modernidad. Buenos Aires. Paidós.
Hernández, E., 2008. "Análisis y evaluación de Políticas culturales: las Políticas del Patrimonio". Revista Anales de Estudios Económicos y Empresariales. Vol. XVIII 263-312, España.

Hite, Katherine, 2013, "Política y Arte de la conmemoración. Memoriales en América latina y España". Santiago., Editorial Mandrágora.

Hobsbawm, Erik y Ranger, Terence, 2002, La Invención de la Tradición. Madrid: Editorial Crítica.

Instituto de Políticas Públicas en Derechos Humanos (Mercosur), 2012. "Principios fundamentales para las políticas públicas sobre sitios de memoria”. Buenos Aires: IPPDH Mercosur.

Jelin, E., 2003. "Los derechos humanos y la memoria de la violencia política y la represión: la construcción de un campo nuevo en las ciencias sociales". Buenos Aires: Cuadernos del IDES N².

Martinic M., 2013. "Las etapas de ocupación”. Tierra del Fuego. Historia, Arquitectura, Territorio. Garcés, E. Santiago: Ediciones $A R Q$.

Nora, P., 2009. "Pierre Nora en les lieux de mémoire". Santiago: Editorial LOM.

Pardo, C., 2008. "Turismo y Patrimonio Industrial". Madrid: Editorial Síntesis.

Prats, Llorens, 1997. "Antropología y Patrimonio”. Barcelona: Editorial Ariel.

Sarlo, B., 2007. Tiempo Pasado. Cultura de la memoria y giro subjetivo. Una discusión. Buenos Aires: Siglo XXI.

Silva, M., y Rojas, M., 2005. "Sufrimiento y desapariciones: el manejo urbano arquitectónico de la memoria urbana traumatizada". VII Seminario de Patrimonio Cultural: Territorios en Conflicto. Santiago: DIBAM. 
